concurrently, the increased blocking of mitogen-activated kinase cascade could be involved. In the additivity induced by HS + PRED and GM + PRED combinations different pathways, the MAPK (HS, GM) and some transcription factors (PRED) simultaneously could play a role. The inhibitory effect of GM on the AA release from mononuclear cells can be a new element in its antiinflammatory actions.

\section{THU0054 REDUCTION OF IL-18 SERUM LEVELS IN RHEUMATOID ARTHRITIS DURING SHORT TERM-TREATMENT WITH INFLIXIMAB}

M Bombardieri, V Pittoni, F Conti, FR Spinelli, A Spadaro, V Riccieri, C Alessandri, R Scrivo, G Valesini. Divisione Di Reumatologia, Università "La Sapienza", Roma, Italy

\subsection{6/annrheumdis-2001.851}

Background IL-18 is a recently identified cytokine thought to play a role in many autoimmune diseases including RA. Initially known as INF $\gamma$-inducing factor, IL-18 was shown to be able to exert its inflammatory actions also upregulating, at least in vitro, other cytokines such as TNF $\alpha$. It has also been shown that TNF $\alpha$ induces the expression of IL-18 in synovial tissues, an observation which raises the possibility of a positive feedback between these two cytokines. It has recently been demonstrated that TNFo-blocking treatments in RA patients result in the down-regulation of serum levels of other proinflammatory cytokines, thus providing an additional anti-inflammatory effect.

Objectives The aim of this study was to measure serum IL-18 levels in RA patients treated with monoclonal anti-TNF $\alpha$ antibody (Infliximab) and to evaluate the main clinical and laboratory parameters.

Methods Ten patients with RA, non responding to DMARDs, were enrolled. Infliximab was administered i.v. at a dose of 3 $\mathrm{mg} / \mathrm{Kg}$ at baseline, after 2, 6 and 14 weeks. Sera from all patients were collected before each infusion and stored at ?20 $2{ }^{\circ} \mathrm{C}$ until tested using an enzyme-linked IL-18 assay. Statistical analysis was performed using non parametric methods for paired samples.

Results Serum IL-18 levels were significantly reduced from baseline value (median $/ 25^{\circ}-75^{\circ}$ percentile $1008 / 465-1676 \mathrm{pg} / \mathrm{ml}$ ) after 2 weeks $(185 / 0-1241 \mathrm{pg} / \mathrm{ml}, \mathrm{p}<0.005), 6$ weeks $(175 / 0$ $644, \mathrm{p}<0.01)$ and 14 weeks $(59 / 0-437, \mathrm{p}<0.02)$. No significant decrease was observed between IL-18 levels at 2, 6 and 14 weeks. After 2 weeks ESR ( $p<0.005)$ and CRP $(p<0.02)$ values were significantly reduced from baseline, while we observed a significant increase in ESR $(p<0.02)$ and CRP $(p<0.03)$ values at 6 weeks as against 2 weeks, without any significant change at 14 weeks. There was a significant decrease from baseline in both the number of tender joints $(\mathrm{p}<0.02)$ and the patient global evaluation of disease activity $(\mathrm{p}<0.02)$ at 6 weeks, while no correlation between serum IL-18 levels and clinical/laboratory parameter was found at any time-point.

Conclusion Our results demonstrate that anti-TNF $\alpha$ therapy downregulates serum IL-18 levels already after 2 weeks of treatment and maintains them significantly lower than the baseline at 6 and 14 weeks. Thus, modulation of IL-18 could contribute to the anti-inflammatory actions of TNF $\alpha$-blocking treatments.

Health services, economics and outcome research
AB0231 PHARMACOECONOMIC ANALYSIS OF THE TREATMENT OF RHEUMATOID ARTHRITIS WITH LEFLUNOMIDE IN COMPARISON WITH THE COMBINATION OF INFLIXIMAB AND METHOTREXATE

${ }^{1} \mathrm{C}$ Rubio-Terrés, ${ }^{1} \mathrm{~F}$ Romero, ${ }^{2} \mathrm{~A}$ Domínguez-Gil. ${ }^{1}$ Pharmacoeconomics Unit Scientific Department, Aventis Pharma, S. A., Madrid, Spain; ${ }^{2}$ Pharmacy Department, Hospital Universitario de Salamanca, Salamanca, Spain

10.1136/annrheumdis-2001.852

\section{Background}

Objectives To carry out a pharmacoeconomic analysis to compare the efficiency of two rheumatoid arthritis treatments in Spain.

Methods The study consisted of a systematic review of efficacy and toxicity as well as a cost-minimization analysis, carried out using a pharmacoeconomic model, comparing the treatment with leflunomide and the combination of infliximab and methotrexate during one year.

Results Clinical trials directly comparing both treatments are not available. The response rate ACR20 combined, after one year, was 53.0\% (CI95\%: 49.2\%-56.4\%) with Leflunomide and 42.0\% (CI95\%: 31.2\%-52.5\%) with the combination of Infliximab and Methotrexate $(\mathrm{P}=0.051)$. There were no statistically significant differences in the ACR50 response (27.0 vs 21.0, respectively; $\mathrm{P}=0.19)$. There were fewer infections with Leflunomide than with the combination, both respiratory $(15.0 \%$ and $34.0 \%$, respectively; $\mathrm{P}=0.0003)$ as well as urinary $(0.0 \%$ and $3.0 \%$, respectively; $\mathrm{P}=0.10)$. In the basic case, the cost per patient of a yearly treatment with Leflunomide or with Infliximab and Methotrexate is estimated to be 315,023 Ptas (Spanish pesetas) (1,893 euros, ?) and 2,596,286 Ptas (15,604 ?), respectively. Therefore, the incremental cost of the combined treatment would be 2,281,263 Ptas (13,711 ?). The sensitivity analysis was carried out using the minimum and maximum costs given by the standard deviations of the unit costs and by modifying other variables, as no significant differences compared to the basic case were found.

Conclusion The cost per patient after one year of treatment is higher with the combination of Infliximab and Methotrexate compared to Leflunomide, this is basically due to the higher acquisition cost of Infliximab.

\section{AB0232 RELIABILITY AND RESPONSIVENESS OF THE RADAI, A SELF-ASSESSED RHEUMATOID ARTHRITIS DISEASE ACTIVITY INDEX}

J Fransen, A Forster, D Uebelhart, BA Michel. Department of Rheumatology and Institute of Physical Medicine, University Hospital Zurich, Zurich, Switzerland

\subsection{6/annrheumdis-2001.853}

Background The Rheumatoid Arthritis Disease Activity Index (RADAI) is a self-administered questionnaire on signs and symptoms of rheumatoid arthritis (RA). The main goal of the RADAI is to evaluate the course of RA disease activity over time. The RADAI consists of 5 items and produces a single index from 0 10; higher scores are indicating higher levels of disease activity. The RADAI has shown to be cross-sectionally valid ${ }^{1}$ and responsive to clinical important worsening of disease activity. ${ }^{2}$

Objectives The study objectives are: 1) to determine the testretest reliability of the RADAI, and 2) to determine if the RADAI is responsive to clinical important improvements in disease 
activity, using an intervention of known efficacy (Infliximab) as external standard.

Methods Until now, 12 RA patients (ACR criteria) have been included (1 male), having high or moderate disease activity (DAS28 >3.2); ${ }^{3} 10$ patients already had a 6-week follow-up. The intervention consisted of treatment with Infliximab and Methotrexate, which is likely to induce a relatively large improvement after 6 weeks. The RADAI was self-administered 1 week before the first infusion with Infliximab (T0). At the first infusion (T1), the patient filled in the RADAI again and the physician assessed the DAS28.

After 6 weeks (T2), the RADAI and the DAS28 were again assessed. For analysis of reliability (T0 and T1) the ICC 3,1 and the Limits-of Agreement [4] were used. Responsiveness was studied by judging the change in RADAI at T2 in relation to the Limits-of-Agreement and the DAS28 response criteria. ${ }^{3}$

Results The RADAI scores at T0 and T1 were mean (sd) 5.0 (1.7) and 4.8 (1.9). The mean (sd) difference was -0.2 (0.8), (paired t-test, $\mathrm{p}=0.41$ ). The ICC 3,1 was 0.89 ( $\mathrm{p}<0.05)$. The Upper Limit-of-Agreement was at 1.6 and the Lower at -2.0. According to the DAS28 response criteria, 3 patients were classified as having no response at T2, 3 had a moderate and 4 a good response. The change in RADAI did not exceed the Lower Limit-of-Agreement for 4 of the 7 responders. The responders had a median (range) change in RADAI of -2.1 ( -0.9 to -8.0$)$, signed rank test, $\mathrm{p}=0.02$ ).

Conclusion The data collection is ongoing till $\mathrm{N}=20$. The first results on reliability and responsiveness are promising. However, if the Limits-of-Agreement turn out to be much wider than -1 and +1 , the reliability of the RADAI should be improved.

\section{REFERENCES}

1 Fransen J, et al. Rheumatology 2000:39(3):321-7

2 Fransen J, et al. Arthritis Rheum., in press

3 Van Gestel AM, et al. Arthritis Rheum. 1998:41(10):1845-50

4 Bland J, Altman D. Lancet 1986;1(8476):307-10

\section{AB0233 PRODUCTIVITY COSTS IN AS. COMPARISON AMONG 3 EUROPEAN COUNTRIES}

${ }^{1} \mathrm{AH}$ Boonen, ${ }^{1} \mathrm{D}$ Van der Heijde, ${ }^{2} \mathrm{M}$ Rutten, ${ }^{3} \mathrm{~F}$ Guillemin, ${ }^{4} \mathrm{M}$ Dougados, ${ }^{5} \mathrm{~K}$ De Vlam, ${ }^{5} \mathrm{H}$ Mielants, ${ }^{1} \mathrm{~A}$ Spoorenberg, ${ }^{6} \mathrm{H}$ Van der Tempel, 'S Van der Linden. ${ }^{1}$ Rheumatology, University Hospital Maastricht, Maastricht; ${ }^{2}$ IMTA, Erasmus University, Rotterdam; ${ }^{3}$ Rheumatology, Ecole Sante Publique, Nancy; ${ }^{4}$ Rheumatology, Hopital Cochin, Paris, France; ${ }^{5}$ Rheumatology, University Hospital Gent, Gent, Belgium; ${ }^{6}$ Rheumatology, Maasland Ziekenhuis, Sittard, The Netherlands

\subsection{6/annrheumdis-2001.854}

\section{Background}

Objectives To compare productivity costs due to inability to perform paid work for ankylosing spondylitis (AS) in three European countries: the Netherlands (NL), France (F) and Belgium (B).

Methods 216 consecutive prevalent out-patients with AS started a 2 year cost-of-illness cohort study. Questionnaires assessed ASrelated health resource utilisation every 2 months. Productivity costs were calculated from societal perspective by friction costs (FC) method (costs of first 3 months of sick-leave) and human capital (HC) approach (costs of sick-leave and work-disability). In addition, loss of income for the patients was assessed. Differences in social security systems among countries were taken into account. Means and 95\% CI after bootstrapping are presented. T-tests were performed on the results of the bootstraps to compare countries.
Results 209 patients completed follow-up. In NL, F and B respectively, 70, 69 and 74\% were male, mean age 46 (SD:12), 38 (SD:12) and 42 (SD:14) yr, mean disease duration 24 (SD:12), 14 (SD:9) and 13 (SD:10) yr and 24, 13 and 24\% had a manual profession.

\begin{tabular}{|c|c|c|c|}
\hline & $\begin{array}{l}\text { NL } \\
(n=131)\end{array}$ & $\begin{array}{l}F \\
(n=53)\end{array}$ & $\begin{array}{l}B \\
(n=26)\end{array}$ \\
\hline Days sick-leave/yr: mean [95\% Cl] & $8.2[4.4-12.6]$ & $4.5[1.5-8.5]$ & $\begin{array}{l}5.3[2.6- \\
11.2]\end{array}$ \\
\hline FC (Euro/pt/yr): mean [95\% Cl] & 556 [316-827] & $\begin{array}{l}324[112- \\
614]\end{array}$ & $274[70-534]$ \\
\hline HC costs (Euro/pt/yr): mean [95\% Cl] & $\begin{array}{l}8862[7100- \\
10630]\end{array}$ & $\begin{array}{l}3188[1190- \\
5729]\end{array}$ & $\begin{array}{l}3609[859- \\
7169]\end{array}$ \\
\hline $\begin{array}{l}\text { Patient income loss (Euro/pt/yr): } \\
\text { mean }[95 \% \mathrm{Cl}]\end{array}$ & $\begin{array}{l}3301[2578- \\
4027]\end{array}$ & $\begin{array}{l}2069[896- \\
3477]\end{array}$ & $\begin{array}{l}1189[300- \\
2269]\end{array}$ \\
\hline
\end{tabular}

Conclusion Productivity costs due to AS are substantial for society and patients and differ among countries. FC underestimate the economic impact of disease. These findings have implications for generalizability of economic studies.

\section{AB0234 OBJEKTIV FUNCTIONAL PERFORMANCE TESTS IN PATIENTS WITH LOW BACK PAIN. REVIEW}

${ }^{1} \mathrm{~K}$ Hanusch, ${ }^{1} \mathrm{~S}$ Hoffmann, ${ }^{2}$ S Satkauskas, ${ }^{1} \mathrm{R}$ Theiler. ${ }^{1}$ Rheumatologie; ${ }^{2}$ Orthopädie, Kantonsspital Aarau, Aarau, Switzerland

10.1136/annrheumdis-2001.855

Background In the past few decades, a large number of physical performance (PP) tests for clinical assessment of patients with low back pain (LBP) have been introduced. Knowledge is limited, however, on the their appropriateness for treatment outcome, clinical and epidemiological studies, which require a high level of reliability and validity of measurements.

Objectives Our review focus on the psychometric properties and clinical usefulness of physical performance measurements in patients with LBP.

Methods In order to comprehensively identify instruments of physical performance measurement in LBP patients and studies on their reliability, validity and clinical usefulness, MEDLINE searches were performed for the time interval from 1998 to 2000 using the following controlled vocabulary: low back pain, measurement (s), outcome, tests, function, physical performance, muscle strength, range of motion, reliability, sensitivity, validity. In the second step reference lists of the retrieved papers were used for identification further studies, which were not included in MEDLINE database. The literature about sophisticated, special equipment requiring functional measurements, which application due to cost and time demand in daily clinical practise is restricted, was excluded from analysis.

Results 162 papers reporting on physical performance tests in patients with low back pain were analysed. Validity and reliability has been more comprehensively studied for ?Timed-up-andgo?, ?Loaded reach? and ?Sit-to-stand? tests. The high level of reliability of these test were reported (correlation coefficients ranged from $r=0,89$ to $r=0.99$ ). No one prospective followup study on responsiveness of PP tests was found. 